\title{
An Application of Two Non-Parametric Techniques to the Prices of British Dwellings: An Examination of Cyclicality
}

\begin{abstract}
Using a Pesaran-Timmermann test of co-movement, Cook and Watson (2015) suggest they have highlighted the 'ripple' effect. Applying this technique but using reference series of the UK, London, Scotland, and three deterministic-periodic series, regional prices are shown to have similar cyclical characteristics, with delays based on distance from London. With periodicities consistent with those revealed by spectral analysis, the deterministic-periodic series reference provides a means of establishing cyclical characteristics avoiding issues concerning variable amplitudes. Although a ripple is revealed, using London as a reference poses problems empirically. What if its cycle is atypical as well as asynchronised?
\end{abstract}

Spectral Analysis, Pesaran-Timmermann test, Ripple Effect

\section{Introduction}

Much is written on house price overspill to neighbouring areas. The UK has been of particular interest featuring a 'ripple effect' that spreads over many regions. It is not uncommon to reassess UK regional house price co-dynamics with a development in time series techniques. Oft cited contributions from Alexander and Barrow (1994) and MacDonald and Taylor (1993) use multiple cointegration to reveal a highly convergent system. Recently, Abbott and De Vita (2013) test for unit root in the differentials between 
pairs of regions. They find almost no convergent pairs. Montagnoli and Nagayasu (2015) find some evidence for convergence clubs. This mixed picture might be a function of the various methods of the empirically driven work and the period of study.

As a 'new technique' in the field, Cook and Watson (2015) use a PesaranTimmermann (1992) (P-T) test to establish co-movement over phases of the London, the reference cycle, and the regions. The P-T test uses binary data so avoiding variability in cycle-amplitude. This approach is used here as the basis for a reconsideration of the ripple effect. Three problems are considered. First, how does an emphasis on cyclicality change the consideration of a ripple effect? Second, what insights does a cyclical emphasis have for analysing UK housing space? Third, are Cook and Watson's (2015) inferences robust?

The article is structured as follows. First, there is a reprise of ripple explanations. A cycle perspective of national and regional series, in an Optimal Currency Area context, is discussed. This is followed by a review of selected literature. Spectral methods and the Pesaran-Timmermann test are described next. Tests of concordance show the cyclical elements have periodic characteristics. It is argued that Cook and Watson's approach could lead to inferences other than a ripple effect, and so should be used with caution. Nevertheless, a useful property of the P-T test is that, whilst assessing co-movement, it is robust against nuisance variability in amplitude, and here reveals persistent delays based on similar, asynchronised, cycles.

\section{Price Diffusion Explanations: the Underpinnings of the Ripple Effect}


For the UK, Meen (1999) defines the ripple effect as the propensity for average house prices to rise first in London and the South East and then spread to the rest of the country. DiPasquale and Wheaton (1996) provide an explanation for price co-movement within an urban area. Although the prices of individual properties are diverse, they vary systematically with their characteristics. What appear as distinguishable markets are part of the same housing market area if there is a tendency towards a stable structure of prices that is not sensitive to cyclical variations. The stability of relative prices is based on 'spatial arbitrage' and the substitutability of, possibly dissimilar properties within a real estate market. Through migration, commuting or switching house-search behaviour, short-term changes in relative prices should be eroded quickly.

Fatas (1997) suggests regional specialisation leads to: asymmetric, industryspecific, shocks; distinct regional cycles; and differences in sensitivity to economic policy initiatives. DiPasquale and Wheaton posit that local housing markets are dependent on local economic conditions. As such, inter-regional house price differentials reflect distinct localised industrial cycles.

Meen (1999) considers a number of causes of inter-regional price dispersion. First, those on a stretched budget may look beyond the local boundary, forcing up prices within a search belt of neighbouring, substitute areas. A second explanation entails taking advantage of differences in house prices. Migrating to take advantage of price differentials would place downward price pressure on the high cost and upward pressures in the low cost region. A third explanation concerns expectations. In the face of an [expected] increased flow of immigrants or even just on the basis of a price shock in a neighbouring region, as in the case of the second explanation, homeowners in one region 
could revise upwards their asking (expected) price. Revised price expectations could replace migration as the transmission mechanism.

The three explanations rely on [potential] migration to maintain regional house price differentials. DiPasquale and Wheaton's intra-urban pricing model relies on switching search behaviour. Thus, migration can be viewed as an intra and inter urban area equilibrating force (Jones and Leishman, 2006). As migration is a weaker equilibrating force between urban areas than within them, price disequilibrium is resolved more slowly nationally and regionally than locally. A further link between these two levels of analysis, due to De Goei et al. (2010), is commuting. They describe the system that operates in the south east of England as monocentric. The implication is that even though regions outside of the London area are classified as separate, they could also be seen as integrated within a very large single urban area.

Meen's (1999) last, and preferred explanation is based on the similarly of the determinants of local house prices. If, say, income increases in all regions at broadly the same rate but with a time lag, then so, perhaps, should house prices. Meen concludes that the dynamics of spatial differentials have little to do with cross border migration. Rather, internal adjustments explain house price differences. If, as he argues, differences in regional economic growth explain variations in house prices, he is not relying on the existence of some sort of pressure-relieving mechanism that favours price transfer from high to low-priced regions.

\section{Applying a Cyclical Perspective to a Regional Model}


De Groot and Franses (2008) suggest there are two views on the presence of economic cycles. Real Business Cycle theory posits that undulations are caused by shocks that are exogenous and are largely unpredictable, and is described here as the shock perspective. The alternative is that cycles are a permanent feature. They are not fully stochastic but partly deterministic. There is not one but a collection of cycles. These, they argue, provide macroeconomic dynamic stability. This is labelled the cycle perspective.

One could argue that the ripple explanations conform more with the shock than the cycle perspective. There is no mention of local housing cycles in Meen's explanations, only spillover or diffusion to or from elsewhere, possibly nearby. A unified market in a cyclic context would be characterised by dominant common periodic elements. This is evident in Artis and Zhang's (1997) analysis of optimal currency areas. Marchand (1981) finds a dominant Juglar cycle operating in an urban system. This commonality could be a reflection of some non-housing, but pervasive, driving force, such as a national business cycle. Inter-urban demand transmission occurs through trading ties and is reflected in minor, three-month cycles. Dominant Juglar cycles are consistent with Meen's assertion that internal adjustments, not migration, is the most likely explanation of a ripple.

A cycle perspective can be explored with a simple optimal currency area (OCA) model where national members' business cycles. With a diverse membership, European economics are expected to converge. De Hann (2008) notes that most OCA convergence studies, for this purpose, use a simple correlation of the cyclical component of GDP. Envisage two adjacent countries that specialise in one industry, each characterised by a distinct single sinusoidal series, which would constitute the business cycle. The business 
cycles would be orthogonal. The monetary authority of the OCA, when setting interest rates would face a challenge. The reference cycle (an average of the national cycles) would correlate with each business cycle with a value of $\sqrt{0.5}$. The cycle orthogonality ensures a complete absence of a measure of national co-movement. Portfolio theory suggests that the distinct national structures results in the OCA having a lower variance than the nations by a factor of 0.5 .

Trade is a key force behind increased EU cycle synchronisation (De Hann, 2008). This can be taken further with intra-industry trade. Here, the 'same' goods traverse borders. The demand cycle of the good would influence the home and the exporting country. Alternatively, if the two goods are related, such that one constitutes intermediate products of the other, the production chains of the two countries' are dependent. These propositions imply that the countries' cycles would be linked through both production chains and consumption functions. Increased trade between the two nations would imprint their business cycles on each other. This will remove the orthogonality and increase the correlation with the reference cycle. The ideal format where common interest rate policy will not be destabilising (De Grauwe, 2003) is where there is a single common sinusoidal periodicity, which is synchronised across the nations. Here, the OCA cycle will correlate with a value of one with the nations.

In this simple framework, common but unsynchronised cycles still present monetary policy-makers with a challenge. Assume a delay or phase shift of $2 D \neq 0$ between the two national cycles with the leading nation modelled by $\cos \left(\omega_{j}-D\right)$ and the following nation by $\cos \left(\omega_{j}+D\right)$. Using $\cos \left(\omega_{j} \pm D\right)=\cos \omega_{j} \times \cos D \mp \sin \omega_{j} \times \sin D$, the reference series can be expressed as $\cos \omega_{j} \times \cos D$. In other words, the OCA will have 
the same cycle as the nations but the amplitude of the OCA's cycle will be $\cos D \times$ either nation's. The correlation of the national cycles with the reference's will again be $\cos D$. By implication, the correlation of the two national series will be $\cos (2 D)$.

The delay, $D$, relative to the cycle periodicity, $\omega$, matters. If $D=1 / 4 \omega_{j}$, the amplitude of the reference series is zero. If $D>1 / 4 \omega_{j}$, the reference series is negatively correlated with the nations. If $2 D=1 / 4 \omega_{j}$, the correlation of the two national cycles is zero, and each is correlated with the reference series with a value of $\sqrt{0.5}$. In other words, the effect of a delay can be the same as distinct business cycles; lower cycle correlations; a smaller reference series variance; and interest rate challenges.

As a ripple in house prices implies a leading and a following region at cycle $\omega_{j}$, three important conclusions emerge from this cycle perspective. First, the measure of cyclical agreement declines as the mix of regional cycles becomes more distinctive. Second, a ripple in a cycle perspective requires common regional cycles. Third, the measure of regional cyclical agreement declines as the delay between the (two) regions is extended.

If the UK market is dominated by London, the region and the rest of the nation would have similar cyclical properties. There would be high coherence (or be attuned to London). The same outcome emerges if there are dominant cycles common to all regions. The ripple effect implies price synchronisation after adjusting for a spatio-temporal lag. To translate Meen's ripple definition, it implies that all regions can be modelled by sinusoidal series that are subject to a phase shift or delay relative to London and the South East. 


\section{House Price Diffusion: Methods and Evidence}

The workhorse for analysing diffusion is the error correction model (ECM). In this context, the ripple involves a deviation from trend earlier by the southern and then later by northern regions. It is exhausted in the long-run, implying common regional price trends and stable house price differentials. Granger-causality is used to expose short run lead-lag relations. There are numerous examples across a variety of countries, such as Alexander and Barrow (1994) (UK), Stevenson (2004) (Eire) and Shi et al. (2009) (New Zealand). Holly et al. (2011) use generalised impulse response functions to show how a house price shock in London diffuses throughout the regional system, broadly in line with a ripple sequence from the south to the north of Britain. There are two requirements for the ECM to be appropriate. All regions follow common trends and that changes in the south precede those in the north. Inferences will be challenging where, rather than one way Granger-causality, feedback is widespread and a leader-follower relationship cannot be inferred, particularly if London is 'caused' by others. Or insufficient causality emerges to illustrate the passage of the ripple from south to north. Another concern is not finding a delay based on distance. Ashworth and Parker (1997) conclude that, following a lag of three or four quarters, South East house prices 'cause' corresponding changes to those in all other UK regions.

Meen (1999) asserts that the regional-national house prices ratio should not exhibit much if any of a long-term trend. In other words, the ratio should be stationary. A Principal Components Analysis approach due to Holmes and Grimes (2008) reveals all regions are pairwise stationary. However, this region-nation approach requires all regions to converging to the national average. If one is diverging, this will affect the reference 
national series (Carvalho and Harvey, 2005). Montagnoli and Nagayasu (2015), when investigating convergence clubs, find London is not convergent with the rest of the UK. As convergence to common trends or to a national reference cycle is central to some inferences of a ripple, their result is problematic for any convergence thesis.

Importantly, convergence or common trends are not a necessary condition for a ripple inference. To trace a ripple or to classify leading regions, one can date turning points. For example, Cook and Thomas (2003) identify the quarter in which the highest [and lowest] growth rate occurs for each area. Gray (2012) shows a ripple band using local indicators of spatial association. Cook and Watson (2015) use a PesaranTimmermann (1992) (P-T) test to establish co-movement between regions and the London reference cycle. Growth turning points are then used to segment the series so that co-movement is examined over phases of the London's price cycle. They infer the ripple effect from declining co-movement measures.

Many papers decomposing series into unobserved elements apply a [HodrickPrescott (H-P)] filter to data to extract a cycle for analysis. Using cross-correlations, Artis and Zhang (1997) examine synchronicity and linkages between the German, H-P filtered, business cycle and those of other ERM members. Akimov et al. (2015) employ a meancorrected index of concordance to assess the degree of commonality in property cycles, distilled by a H-P and a Beverage-Nelson filter. Cook (2003) finds that allowing for asymmetry in the cycle reveals more dimensions to the long-run region-nation meanreversion. Cook (2006) confirms asymmetry in filtered regional house price across vintages. 
In examining house price diffusion among British regional and Irish city markets, using spectral analysis, Gray (2015: 2013) finds dominant periodicities of 7.5 and of 6.4years respectively. The bonding between Irish housing markets is strong at the key cycle but there is not much evidence of a ripple in the sense that is understood in the UK.

\section{Methodology}

A time series $X_{t}$ can be seen as comprising a growth or trend element $g_{t}$ and a cyclical element $x_{t}$ such that $X_{t}=g_{t}+x_{t}$. Hodrick-Prescott filter (H-P) smooths out $X$ so as to distil the cyclical component, $x_{t}$. For quarterly data, the smoothing factor is commonly set to 1600 .

Spectral analysis is a means of revealing periodicities within a stationary time series in what is called the frequency domain. The theoretical power spectrum reveals the contribution to total variance (relative power) at each frequency in the spectrum. So if the spectral density (power) has a large value at frequency $\omega_{j}$, it indicates that variable $X$ has a concentration of variance at that periodicity. The power spectrum is given by $s_{x, x}(\omega)=\frac{1}{2 \pi} \sum_{k=-\infty}^{\infty} \gamma_{x, x}^{(k)} \cos (\omega k) \quad$ (Hamilton 1994). The cross spectrum, given by, $s_{x, y}(\omega)=\frac{1}{2 \pi} \sum_{k=-\infty}^{\infty} \gamma_{x, y}^{(k)}(\cos (\omega k)+i \sin (\omega k))$, can be broken down into the real and imaginary parts, $s_{x, y}(\omega)=c_{x, y}(\omega)-i q_{x, y}(\omega)$. A cospectrum value at frequency $\omega_{j}$ indicates the relative degree of covariance of $X$ and $Y$ at that periodicity in the frequency domain (Hamilton, 1994). The theoretical cospectrum is given by $c_{x, y}(\omega)=\frac{1}{2 \pi} \sum_{k=-\infty}^{\infty} \gamma_{x, y}^{(k)} \cos (\omega k)$. Coherence is the frequency domain's equivalent of the 
coefficient of determination $\left(R^{2}\right)$. The squared coherence is given by $C_{x, y}{ }^{2}(\omega)=\frac{\left|s_{x, y}(\omega)\right|^{2}}{s_{x, x}(\omega) s_{y, y}(\omega)}($ Jenkins and Watts, 1968). Ranging between zero and one, a value is unimportant if there is no spike in the power spectrum in both $X$ and $Y$ at that frequency.

The phase value gives a notion of leading of $X$ over $Y$. The phase angle $P_{x, y}(\omega)=\tan ^{-1} \frac{-q_{x, y}(\omega)}{c_{x, y}(\omega)}$ can be converted into the time shift tau $\tau=$ phase value/angular frequency. Coherence can be interpreted as if the series $X$ lagged sufficiently to eliminate any asynchronisation with $Y$ (Levy, 1994). High coherence and common regional peaks in the power spectra would be indicative of common cycles. The ripple, revealed by phase, should be evident at cycles with high power.

The Pesaran-Timmermann test is a non-parametric test of independence between binary time series, $X$ and the reference series, $Y$. Define $I\left(X_{t}\right)=1$ if $X_{t}>0$ and 0 otherwise, so that $X_{t}$ is binary. Then take the mean, $\bar{I}_{X}=N^{-1} \sum_{i=1}^{N} I\left(X_{t}\right)$. Repeat this for $Y_{t}$ and the cross product term $X_{t} Y_{t}$ such that $\bar{I}_{X Y}=N^{-1} \sum_{i=1}^{N} I\left(X_{t} Y_{t}\right) . P_{*}$ is defined as $\bar{I}_{X} \bar{I}_{Y}+\left(1-\bar{I}_{X}\right)\left(1-\bar{I}_{Y}\right)$. Variances of $\bar{I}_{X Y}$ and $P_{*}$ are then given by $V\left(\bar{I}_{X Y}\right)=N^{-1} P_{*}\left(1-P_{*}\right)$ and $V\left(P_{*}\right)=N^{-1}\left(2 \bar{I}_{Y}+1\right)^{2} \bar{I}_{X}\left(1-\bar{I}_{X}\right)+N^{-1}\left(2 \bar{I}_{X}+1\right)^{2} \bar{I}_{Y}\left(1-\bar{I}_{Y}\right)+4 N^{-2} \bar{I}_{X} \bar{I}_{Y}\left(1-\bar{I}_{X}\right)\left(1-\bar{I}_{Y}\right)$. The statistic P-T $=\frac{\bar{I}_{X Y}-P_{*}}{\sqrt{V\left(\bar{I}_{X Y}\right)-V\left(P_{*}\right)}} \stackrel{a}{\sim} N(0,1)$ can be used to test the null that $X$ and $Y$ do not have synchronised movements. 
The P-T test of concordance is applied in three ways. The first considers the regional house price data in differences $\left(\Delta X_{t}\right)$ to reflect Cook and Watson's approach. The second uses the filtered cyclical element $x_{t}$. As the cyclical element is also subject to spectral methods, the outcomes are compared. Montagnoli and Nagayasu's (2015) finding plus Fernandez et al.'s (2016) thesis that the London property is a safe haven for an international, wealthy, elite, imply that it would have dissimilar cycles to the rest of the UK. As such, the UK is preferred to London as the reference.

The third application of the P-T test involves the sinusoidal time series $Y_{t}=$ $\cos \left(\omega_{j}\right)$ which are used as reference cycles. Consistent with above, these values are converted into binary. If a house price 'cycle' time series does not have sinusoidal characteristics, it crosses the abscissa at random intervals. As such, there will not be comovement with a deterministic-periodic series. The P-T tests whether $x_{t}$ corresponds with the periodicity of the synthesised variable. It is a means of distinguishing between a cycle, which predicts periodicity, and a shock perspective, which does not.

Distinctive local housing cycles will be reflected in non-concordance. Concordance also declines with the asynchronisation inherent in a ripple. Thus, concordance could reveal how attuned are regions to each other and to a national cycle assuming adjustments for asynchronicity.

\section{Data}

The regional data are drawn from the Nationwide Building Society's web site for the period 1983Q1 to 2014Q4, subdivided by buyer type. This data set is quoted widely in academic papers. Holmes and Grimes (2008) utilise this source, and Cook and Watson 
(2015) use both Halifax and Nationwide data; the former from 1983, and the latter a decade earlier. They use changes in house prices. In this paper, the analysis involves the unobserved cyclical elements of logged data. As such, they are not directly comparable but have strong similarities. The data also is of repeat buyer prices. As this group is favoured by rising prices (Stein, 1995) and housing finance can also accelerate procyclical dynamics (Aoki, et al., 2004) these should have stronger cyclical properties than for all buyers.

As is evident from Table 1, over the 32 years, house prices in the UK grew considerably. The ratio of the highest to the lowest price, after removing the cyclical element, is 6.88. In other words, house prices grew in nominal terms just under seven times. Here, four regions outshone the UK (South West, Outer South East, Outer Metropolitan and London). London prices grew by a factor of 10.25 , over twice as rapidly and the slowest growing region, Scotland (4.98).

Table 1 House Price Levels and Trends

\begin{tabular}{|c|c|c|c|c|c|c|c|}
\hline & EA & EM & LON & OMET & OSE & SW & UK \\
\hline Price High & $£ 203989$ & $£ 170354$ & $£ 437439$ & $£ 324203$ & $£ 251466$ & $£ 223063$ & $£ 205714$ \\
\hline Price Low & $£ 30481$ & $£ 27507$ & $£ 42667$ & $£ 43471$ & $£ 35013$ & $£ 31248$ & $£ 29901$ \\
\hline Difference & $£ 173509$ & $£ 142847$ & $£ 394772$ & $£ 280732$ & $£ 216454$ & $£ 191815$ & $£ 175813$ \\
\hline $\begin{array}{r}\text { Growth } \\
\text { rate } \\
\end{array}$ & 6.692 & 6.193 & 10.252 & 7.458 & 7.182 & 7.139 & 6.880 \\
\hline & NO & NW & SC & WA & WM & $\mathrm{YH}$ & $\mathrm{NI}$ \\
\hline Price High & $£ 149312$ & $£ 172423$ & $£ 156311$ & $£ 164347$ & $£ 178467$ & $£ 164169$ & $£ 179730$ \\
\hline Price Low & $£ 26711$ & $£ 29064$ & $£ 31380$ & $£ 28431$ & $£ 28957$ & $£ 24780$ & $£ 29584$ \\
\hline Difference & $£ 122601$ & $£ 143359$ & $£ 124932$ & $£ 135915$ & $£ 149509$ & $£ 139389$ & $£ 150145$ \\
\hline $\begin{array}{r}\text { Growth } \\
\text { rate }\end{array}$ & 5.590 & 5.932 & 4.981 & 5.780 & 6.163 & 6.625 & 6.075 \\
\hline
\end{tabular}

EA=East Anglia, EM=East Midlands, LON=Central London, NI=Northern Ireland, NO=North, NW=North West, OMET=Outer Metropolitan, LON=London, OSE=Outer South East, SC=Scotland, SW=South West, WA=Wales, WM=West Midlands, YH=Yorkshire/Humberside, UK=United Kingdom. 
The cyclical element is also explored, comparing the regions with the UK. Here, the UK has the second smallest standard deviation (0.046), which is taken to represent house price volatility. The smallest volatility measure in Table 2 is to be found in Scotland. The most volatile regions are somewhat of a mixed bag. Wales, East Anglia and the South West have no obvious link. Pearson's correlation coefficient is reported as 'Corr'. The values show the closest similarity with the UK is the East Midlands, followed by West Midlands and Outer South East, not London. Cyclicality is illustrated in Figure 1.

Figure 1 Cyclical Co-movement for Selected Regions

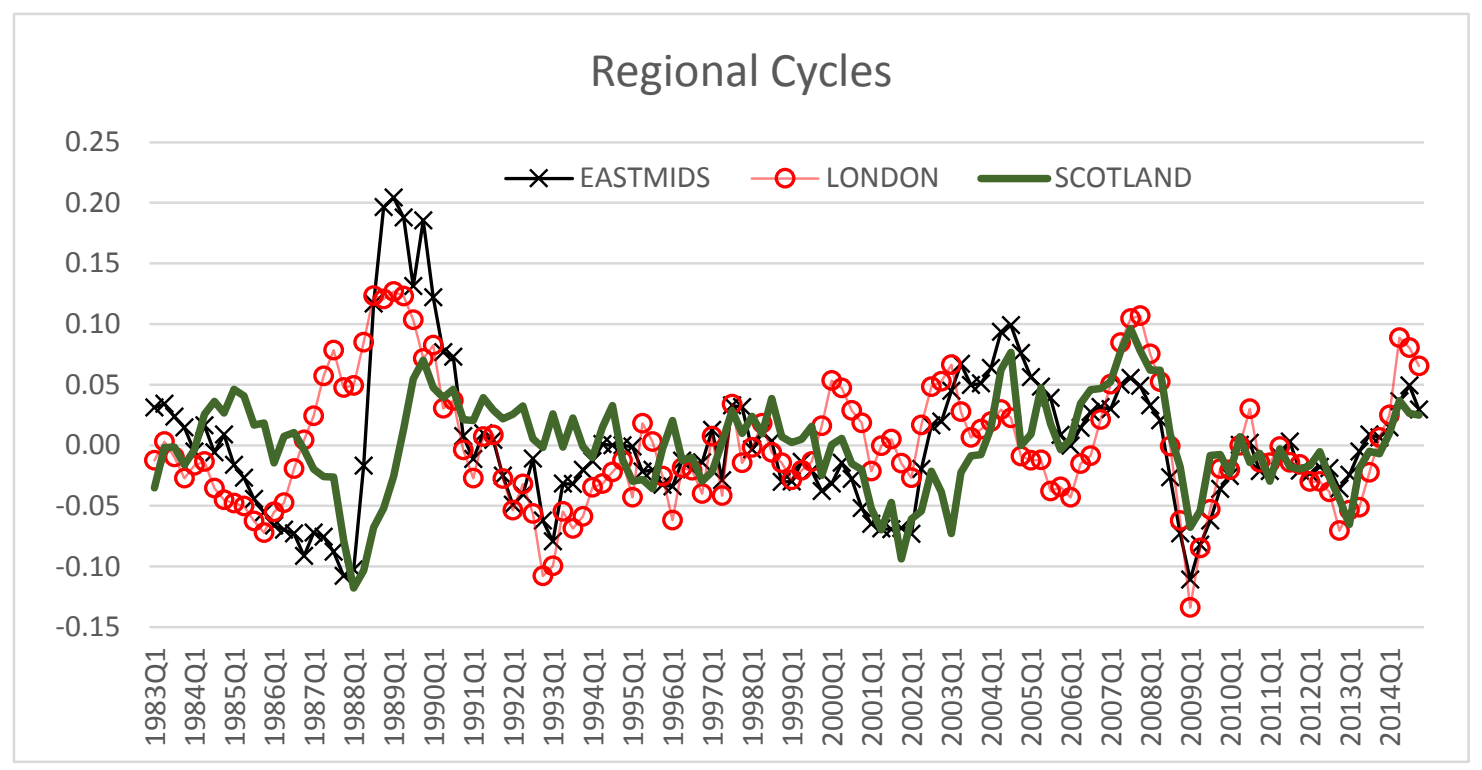

Table 2 Measures of Agreement with the UK

\begin{tabular}{|c|c|c|c|c|c|c|c|c|c|c|c|c|c|}
\hline & \multirow[t]{2}{*}{ SD } & \multirow[t]{2}{*}{ Corr } & \multicolumn{2}{|c|}{$\begin{array}{c}\text { Detrended } \\
x_{t}>0\end{array}$} & \multicolumn{2}{|c|}{$\begin{array}{c}\text { Difference } \\
\Delta X_{t}>0\end{array}$} & & \multirow[t]{2}{*}{ SD } & \multirow[t]{2}{*}{ Corr } & \multicolumn{2}{|c|}{$\begin{array}{c}\text { Detrended } \\
x_{t}>0\end{array}$} & \multicolumn{2}{|c|}{$\begin{array}{c}\text { Difference } \\
\Delta X_{t}>0\end{array}$} \\
\hline & & & Kappa & P-T & Kappa & P-T & & & & Kappa & P-T & Карра & P-T \\
\hline SC & 0.038 & .448. & .373 & 4.250 & .302 & 3.417 & EA & 0.062 & 847 & .729 & 8.284 & .522. & 5.919 \\
\hline NO & 0.059 & .576 & .440 & 5.056 & .363 & 4.117 & EM & 0.059 & .946 & .778 & 8.834 & .525 & 5.862 \\
\hline YH & 0.058 & .779. & .535 & 6.183 & .402 & 4.528 & SW & 0.062 & .843 & .792 & 9.011 & .620 & 6.950 \\
\hline WA & 0.062 & 818 & .509 & 5.781 & .412. & 4.668 & LON & 0.051 & .766 & .505 & 5.742 & .673. & 7.499 \\
\hline NW & 0.056 & .755 & .639 & 7.275 & .574 & 6.417 & OMET & 0.049 & .845 & .670 & 7.633 & .702 & 7.818 \\
\hline WM & 0.059 & 940 & 810 & 9.208 & 582 & 6.523 & OSE & 0.056 & .904 & .648 & 7.375 & .746 & 8.327 \\
\hline
\end{tabular}


Cook and Watson (2015) test co-movements across an entire period and sub-periods, relating them to London. Kappa measures the extent of agreement between two judges using categorical data. The range of values is -1 to 1 , with 0 indicating no agreement and +1 indicating perfect agreement. When dealing with binary data, the Kappa measures of association of agreement are very close to other of Cramer's $V$, Phi and Spearman's and Pearson's correlation coefficients. Kappa's approximate T-value is very close to the P-T value. As Kappa is more interpretable, the presentation in Table 2 shows the Kappa value and the P-T coefficient. The highest level of agreement is between the West Midlands and the UK, followed by the South West, East Midlands and East Anglia. These form a ring around Outer South East. This is slightly different from the correlation picture mentioned above. However, those furthest away from the Midlands still have the lowest values.

Kappa is generated based on the house prices differenced, which are comparable with Cook and Watson, but using the UK rather than London as the reference cycle. Values do decrease with distance from the south east, but not all. By all three measures of agreement with the UK, London is not the most attuned region, putting a question against it as a reference cycle. Indeed, when London is used as the reference (not reported), three regions are found not to be concordant with it.

The power spectra for most of the regions appear very similar, with a concentration of power in three cycles. The Power values in Table 3 correspond with the standard deviation values in Table 2. Scotland has lower values than the UK. London and Outer Metropolitan have lower values than the UK's at two and all three cycles respectively, signifying they are not the most volatile regions. 
The lowest cospectrum values are associated with the two extremes, Scotland, the North, London and Outer Metropolitan. This is duplicated by coherence. The highest values are to be found in the Midlands and South West. These results are not consistent with London driving the rest of the UK.

Table 3 Spectral Values at the Dominant Cycles

\begin{tabular}{|c|c|c|c|c|c|c|c|c|c|c|}
\hline $\begin{array}{l}\text { Cycle } \\
\text { years }\end{array}$ & Region & Coh & Co & Power & Phase & Region & Coh & Co & Power & Phase \\
\hline 6.40 & \multirow{3}{*}{ EA } & 0.966 & 0.149 & 0.230 & -1.847 & \multirow{3}{*}{ NO } & 0.597 & 0.096 & 0.196 & 2.628 \\
\hline 8.00 & & 0.959 & 0.122 & 0.188 & -2.421 & & 0.544 & 0.088 & 0.236 & 3.587 \\
\hline 10.67 & & 0.976 & 0.126 & 0.162 & -2.605 & & 0.760 & 0.119 & 0.188 & 2.801 \\
\hline 6.40 & \multirow{3}{*}{ LON } & 0.780 & 0.092 & 0.108 & -1.853 & \multirow{3}{*}{ NW } & 0.860 & 0.125 & 0.208 & 2.344 \\
\hline 8.00 & & 0.691 & 0.086 & 0.131 & -2.546 & & 0.797 & 0.110 & 0.209 & 2.971 \\
\hline 10.67 & & 0.756 & 0.093 & 0.119 & -3.006 & & 0.907 & 0.133 & 0.199 & 2.814 \\
\hline 6.40 & \multirow{3}{*}{ OMET } & 0.877 & 0.093 & 0.102 & -1.939 & \multirow{3}{*}{ SC } & 0.773 & 0.025 & 0.062 & 5.046 \\
\hline 8.00 & & 0.771 & 0.077 & 0.093 & -2.472 & & 0.651 & 0.021 & 0.077 & 6.499 \\
\hline 10.67 & & 0.839 & 0.095 & 0.104 & -2.417 & & 0.778 & 0.042 & 0.079 & 7.165 \\
\hline 6.40 & \multirow{3}{*}{ OSE } & 0.943 & 0.142 & 0.200 & -1.533 & \multirow{3}{*}{ WA } & 0.904 & 0.142 & 0.198 & 1.193 \\
\hline 8.00 & & 0.936 & 0.121 & 0.182 & -2.240 & & 0.807 & 0.115 & 0.176 & 1.740 \\
\hline 10.67 & & 0.972 & 0.122 & 0.155 & -2.822 & & 0.886 & 0.134 & 0.186 & 1.747 \\
\hline 6.40 & \multirow{3}{*}{ SW } & 0.975 & 0.146 & 0.196 & -1.290 & \multirow{3}{*}{ WM } & 0.979 & 0.168 & 0.235 & 0.290 \\
\hline 8.00 & & 0.973 & 0.126 & 0.175 & -1.755 & & 0.962 & 0.144 & 0.206 & 0.370 \\
\hline 10.67 & & 0.979 & 0.131 & 0.162 & -1.873 & & 0.964 & 0.146 & 0.189 & 0.344 \\
\hline 6.40 & \multirow{3}{*}{ EM } & 0.967 & 0.164 & 0.223 & -0.051 & \multirow{3}{*}{$\mathrm{YH}$} & 0.823 & 0.125 & 0.189 & 1.833 \\
\hline 8.00 & & 0.942 & 0.138 & 0.193 & -0.080 & & 0.704 & 0.109 & 0.211 & 2.587 \\
\hline 10.67 & & 0.958 & 0.146 & 0.191 & -0.353 & & 0.817 & 0.131 & 0.207 & 2.520 \\
\hline & UK & $6.4 y$ & 0.117 & UK & $8.00 y$ & 0.105 & UK & $10.67 y$ & 0.124 & \\
\hline
\end{tabular}

$\mathrm{Co}=$ cospectrum, $\mathrm{Coh}=$ coherence , Power $=$ power spectrum. Key to regions, see Table 1

\section{Delays at Key Cycles}

Calibrated using the highest Kappa between each binary cyclical series and the reference cycle, three variables of 25, 32 and 45 periodicities are generated. These correspond closely with the three spectrally-revealed periodicities. As the frequencies assessed with spectral analysis are determined by $k \div N$, where $k=1,2,3 \ldots 0.5 N$, it is to be expected that with low values of $k$ the match with the Kappa cycles is not perfect. 
Broadly, Kappa in Tests of concordance reported in Table 4 between the UK and a six-year cycle show a null of zero co-movement is rejected $($ Kappa $=.287, \mathrm{P}-\mathrm{T}=3.316$ [.001]). It is concluded that, consistent with the spectral analysis, the UK house prices contain a six-year cycle. It may appear that not all regions have this cycle, but this is not the case. Using London and Scotland for calibration, the tests are repeated to accommodate a different phase. Although not so attuned, Table 5 indicates that Scotland, Outer Metropolitan and London, also contain the six-year cycle. Kappa indicates London leads the UK by six quarters; Scotland lags by four; and the southern regions of OSE, EA and SW are somewhere in between. The negative signs imply the northern regions are out of phase by over a quarter of a cycle.

London has a higher Kappa value (Table 5) if assessed at a point 5 quarters earlier than the UK (Table 4). Otherwise, most other regions exhibit co-movement with the 8year cycle at the 5\% level with and without the phase adjustment. The 11-year cycle highlights themes raised earlier. London and Outer Metropolitan are out of phase with the rest, leading them by 15 quarters. The Kappa values are lower with the 11 year cycle. ${ }^{\mathrm{i}}$

It is clear that the P-T/Kappa value is dependent on phase. By synchronising cycles, the realignment and the greater Kappa reveal delays relative to the reference cycle. The results point to London and Outer Metropolitan leading the rest by between 5 and 15 quarters.

The phase values are reported in quarters in Table 3. At the 6.4-year cycle, London precedes the UK by 1.8 quarters, with the East Midlands broadly synchronised and Scotland five quarters behind. A ripple takes seven quarters to cross the mainland 
Britain. The differential between the two extremes is magnified with the other two cycles, but the picture is unchanged.

The spectral results and Kappa do not present a major disagreement over order, just delay. In the main, the leader characteristics of London and Outer Metropolitan, and Scotland as a follower are confirmed. The Midlands have values that most closely reflect the UK's.

\section{Issues}

The spectral coefficients and Kappa values indicate that that there are three major cycles that characterise house prices. The inferences from P-T tests using binary data in the time domain are unaffected by the financial acceleration effects on price amplitudes that Cook (2006) considers. It is concluded that regional house price series correspond with a cycle perspective. Two key theoretical implications emerge. First, the agreement between regional cycles and simple deterministic periodic variables suggesting that undulations are largely periodic is inconsistent with Real Business cycle theory. Second, unlike Marchand (1981), the delays consistent with a ripple thesis are revealed by spectral analysis at major, not minor cycles. This is distinction is consistent with Meen's (1999) preferred ripple explanation, and a cycle perspective: regional cycles are similar, but are subject to regionally specific delays.

Some empirics can also be explained. The UK has a lower standard deviation than most regions, which results from both the portfolio effect and the ripple effect. Also, the agreement values put the UK attuned with the Midlands regions whilst London and Scotland are less well aligned. Again, this can be explained by both ripple and portfolio 
theses. A common cycle with delay results in centrally-placed regions appearing attuned to the national cycle. Alternatively, the geographical extremes are also distinctive housing market areas. Thanos and White (2014) discuss the house auction system in Scotland that is atypical. Montagnoli and Nagayasu (2015) arguments rather than their (trend) results imply that London has distinctive cycles, possibly as a result of it being linked into a global financial system (Fernandez et al., 2016; Holly, et al., 2011).

A ripple effect has been revealed in the UK by spectral analysis. It is generally consistent across the three cycles. A six-quarter lag between north and south is quicker than that revealed by Gray (2012) but interestingly, the less discriminating P-T tests point to a general delay but longer than Ashworth and Parker (1997) by at least six months.

When drawing inferences from P-T values that decline with distance from the Capital, Cook and Watson (2015) have not distilled a 'distinct cycles'/ portfolio effect from a ripple effect. Using the leading region, London, as the reference lowers agreement coefficients relative to using the UK. As the London housing market is distinctive, this is exaggerated, signifying less UK integration than might actually exist.

\section{Conclusion}

This paper reconsiders work on co-movement among regional house price series using two methods. Generating a deterministic periodic series, Pesaran-Timmermann tests confirm co-movement with the regional cycles. This method provides a means of establishing periodic characteristics avoiding variable cycle amplitude. However, inferences are shown to be dependent on phase, and the test could confuse distinctive cyclical characteristics with the ripple effect. 
Spectral methods reveal southern regions lead the Midlands by around 2 to 3 quarters and the Midlands leading the northern regions by $2^{1 / 2}$ to $3^{1 / 2}$ quarters, with Scotland double that lag, in line with a ripple thesis. These delays occur at $10^{2} / 3,8$ and 6.4-year cycles. In the time domain, all regions can be modelled by deterministic periodic series that are subject to phase shifts or delays. Adjustments for asynchronicity indicate that London and Outer Metropolitan lead the rest by between 5 and 15 quarters. With the exception of Scotland, other regions are synchronised with the UK. This is more in line with Ashworth and Parker (1997), but with some regional variation than a ripple thesis.

Consistent with Meen's (1999) preferred ripple explanation, overlaid on trends, the cycle perspective implies that there are stable, common, dominant regional periodicities. Delays vary with distance from London. This points to further research into why regional cycles are common yet not synchronised. This has implications for inferences of convergence and regional economic integration using measures of agreement.

Cyclical convergence is desirable characteristic of optimal currency areas. Without it, common interest rate policy will be destabilising (De Grauwe, 2003). This problem applies to common but asynchronised regional cycles. If national interest rate policy is geared towards managing house price inflation in the leading region and that is out of phase with the following region, seeking to moderate the cycle amplitude in one will exaggerate the other. This highlights the need for non-interest rate policy for UK house price management. For instance, multiples or other lending criteria or capital gains tax could focus on moderating financial accelerator-cyclical effects. 


\section{References}

Akimov, A., Stevenson, S. and Young, J. (2015) Synchronisation and Commonalities in Metropolitan Housing Market Cycles, Urban Studies, Vol. 52(9), pp. 1665-1682.

Aoki, K., Proudmand, J. and Vlieghe, G. (2004) House Prices, Consumption and Monetary Policy: a Financial Accelerator Approach, Journal of Financial Intermediation, Vol. 13, pp. 414-435.

Artis, M. and Zhang, W. (1997) International Business Cycles and the ERM: Is There a European Business Cycle?, International Journal of Finance \& Economics, Vol. 2(1), pp. 1-16.

Ashworth, J., and Parker S. (1997) Modelling Regional House Prices in the UK, Scottish Journal of Political Economy, Vol. 44, pp. 225-246.

Bracke, P. (2013) How Long to Housing Cycles Last? A Duration Analysis for 19 OECD Countries, Journal of Housing Economics, Vol. 22, pp. 213-230.

Carvalho, V. and Harvey, A (2005) Growth, Cycles and Convergence in US Regional Time Series, International Journal of Forecasting, Vol. 21, pp. 667-686.

Cook, S. (2003) The Convergence of Regional House Prices in the UK, Urban Studies, Vol. 40(11), pp. 2285-94.

Cook, S. (2006) A Disaggregated Analysis of Asymmetrical Behaviour in the UK Housing Market, Urban Studies, Vol. 43(11), pp. 2067-2074.

Cook, S. and Watson, D. (2015) A New Perspective on the Ripple Effect in the UK Housing Market: Co-movement, Cyclical Subsamples and Alternative Indices, Urban Studies, Vol. 53(14), pp. 3048-3062. 
De Goei, B., Burger, M., Van Oort, F. and Kitson M. (2010) Functional Polycentrism and Urban Network Development in the Greater South East, United Kingdom: Evidence from Commuting Patterns, 1981-2001, Regional Studies, Vol. 44(9), pp. 1149-1170.

De Grauwe, P. (2003) The Economics of Monetary Integration, $5^{\text {th }}$ ed., Oxford: OUP.

De Groot, B. and Franses, P. (2008) Stability Though Cycles, Technological Forecasting and Social Change, Vol. 75, pp. 301-311.

De Haan, J., Inklaar, R. and Jong-A-Pin, R. (2007) Will Business Cycles in the Euro Area Converge? A Critical Survey of Empirical Research, Journal of Economic Surveys, Vol. 22(2), pp. 234-273.

DiPasquale, D. and Wheaton, W. (1996) Urban Economics and Real Estate Markets, Prentice Hall: Englewood Cliffs, NJ, USA.

Fatas, A. (1997) EMU: Countries or Regions? Lessons from the EMS Experience, European Economic Review, Vol. 41, pp. 743-751.

Fernandez, R., Hofman, A. and Albers, M. (2016) London and New York as a Safe Deposit Box for the Transnational Wealth Elite, Environment and Planning A, Vol. 48(12), pp. 2443-2461.

Gray, D. (2012) District House Price Movements in England and Wales 1997-2007: An Exploratory Spatial Data Analysis Approach, Urban Studies, 49(7), pp. 1411-1434.

Gray, D. (2013) House Price Diffusion: An Application of Spectral Analysis to the Prices of Irish Second-Hand Dwellings, Housing Studies, Vol. 28(7), pp. 869-890.

Gray, D. (2015) Are Prices of New Dwellings Different? A Spectral Analysis of UK Property Vintages, Cogent Economics and Finance, Vol. 3(1), pp.1-16. 
Hamilton, J. (1994) Time Series Analysis, Princeton, New Jersey, USA: Princeton University Press.

Holly, S., Pesaran, H. \& Yamagata, T. (2011) The Spatio-Temporal Diffusion of House Prices in the UK, Journal of Urban Economics, Vol. 69(1), pp. 2-23.

Holmes, M. and Grimes, A. (2008) Is There Long-run Convergence among Regional House Prices in the UK? Urban Studies, Vol. 45(8), pp. 1531-1544.

Jenkins, G. and Watts, D. (1968) Spectral Analysis and Its Applications, London: Holden-Day.

Jones, C. and Leishman, C. (2006) Spatial Dynamics of the Housing Market: An Interurban Perspective, Urban Studies, Vol. 43(7), pp. 1041-1059.

Levy, D. (1994) Output, Capital and Labor in the Short and Long Run, Southern Economic Journal, Vol. 60(4), pp. 946-960.

Marchand, C. (1981) Maximum Entropy Spectra and the Spatial and Temporal Dimensions of Economic Fluctuations in an Urban System, Geographical Analysis, Vol. 13(2), pp. 95-116.

Meen, G. (1999) Regional House Prices and the Ripple Effect: A New Interpretation, Housing Studies, Vol. 14(6), pp. 733-753.

Montagnoli, A. and Nagayasu, J. (2015) UK House Price Convergence Clubs and Spillovers, Journal of Housing Economics, Vol. 30, pp. 50-58.

Pesaran, M. and Timmermann, A. (1992) A Simple Non-Parametric Test of Predictive Performance, Journal of Business and Economic Statistics, Vol. 10, pp. 461-465.

Shi, S., Young, M, and Hargreaves, B. (2009) The Ripple Effect of Local House Price Movements in New Zealand, Journal of Property Research, Vol. 26(1), pp. 1-24. 
Stein, J. (1995) Prices and Trading Volume in the Housing Market: a Model with Downpayment Effects, The Quarterly Journal of Economics, Vol. 110, pp. 379-405.

Thanos, S. and White, M. (2014) Expectation Adjustment in the Housing Market: Insights from the Auction System in Scotland, Housing Studies, Vol. 29(3), pp. 339-361. 
Table 4 In Phase Kappa and P-T values

\begin{tabular}{|c|c|c|c|c|c|c|c|c|c|}
\hline & \multicolumn{3}{|c|}{25 Quarter Cycle } & \multicolumn{3}{|c|}{32 Quarter Cycle } & \multicolumn{3}{|c|}{45 Quarter Cycle } \\
\hline LON & 0.212 & 2.471 & {$[.013]^{\star}$} & 0.141 & 1.621 & {$[.105]$} & -0.021 & -0.242 & {$[.809]$} \\
\hline OMET & 0.081 & 0.923 & {$[.356]$} & 0.234 & 2.665 & {$[.008]^{\star *}$} & 0.014 & 0.161 & {$[.872]$} \\
\hline OSE & 0.228 & 2.67 & {$[.008]^{\star *}$} & 0.219 & 2.529 & {$[.011]^{*}$} & 0.183 & 2.101 & {$[.036]^{*}$} \\
\hline EA & 0.243 & 2.832 & {$[.005]^{\star *}$} & 0.297 & 3.423 & {$[.001]^{* *}$} & 0.199 & 2.281 & {$[.011]^{*}$} \\
\hline EM & 0.287 & 3.316 & {$[.001]^{\star *}$} & 0.469 & 5.366 & {$[.000]^{* *}$} & 0.278 & 3.177 & {$[.001]^{\star *}$} \\
\hline WM & 0.285 & 3.282 & {$[.001]^{\star *}$} & 0.469 & 5.348 & {$[.000]^{* *}$} & 0.405 & 4.603 & {$[.000]^{* *}$} \\
\hline SW & 0.212 & 2.471 & {$[.013]^{\star}$} & 0.391 & 4.504 & {$[.000]^{* *}$} & 0.262 & 3.002 & {$[.003]^{* *}$} \\
\hline WA & 0.24 & 2.762 & {$[.006]^{\star *}$} & 0.422 & 4.821 & {$[.000]^{* *}$} & 0.389 & 4.427 & {$[.000]^{* *}$} \\
\hline $\mathrm{YH}$ & 0.278 & 3.162 & {$[.002]^{\star *}$} & 0.469 & 5.335 & {$[.000]^{* *}$} & 0.501 & 5.715 & {$[.000]^{* *}$} \\
\hline NW & 0.268 & 3.06 & {$[.002]^{\star *}$} & 0.547 & 6.218 & {$[.000]^{* *}$} & 0.358 & 4.072 & {$[.000]^{* *}$} \\
\hline NO & 0.186 & 2.113 & {$[.035]^{*}$} & 0.5 & 5.682 & {$[.000]^{\star *}$} & 0.376 & 4.275 & {$[.000]^{\star *}$} \\
\hline SC & 0.033 & 0.378 & {$[.705]$} & 0.406 & 4.617 & {$[.000]^{\star *}$} & 0.187 & 2.121 & {$[.034]^{\star}$} \\
\hline UK & 0.287 & 3.316 & {$[.001]^{\star *}$} & 0.5 & 5.724 & {$[.000]^{\star *}$} & 0.216 & 2.461 & {$[.014]^{\star}$} \\
\hline
\end{tabular}

Key to regions, see Table 1. * sig at the $5 \%$ level, ** sig at the $1 \%$ level.

Table 5 Out of Phase Kappa and P-T values

\begin{tabular}{|c|c|c|c|c|c|c|c|c|c|}
\hline & \multicolumn{3}{|c|}{25 Quarter Cycle -6Q } & \multicolumn{3}{|c|}{32 Quarter Cycle -5Q } & \multicolumn{3}{|c|}{45 Quarter Cycle -15Q } \\
\hline & Kappa & P-T & $p$-value & Карра & P-T & $p$-value & Kappa & $P-T$ & $p$-value \\
\hline LON & 0.273 & 3.193 & {$[.001]^{\star *}$} & 0.172 & 1.982 & {$[.048]^{*}$} & 0.27 & 3.126 & {$[.002]^{\star \star}$} \\
\hline OMET & 0.174 & 1.992 & {$[.046]^{*}$} & 0.234 & 2.665 & {$[.008]^{* *}$} & 0.173 & 1.972 & {$[.049]^{*}$} \\
\hline OSE & 0.259 & 3.032 & {$[.002]^{\star *}$} & 0.281 & 3.252 & {$[.001]^{\star *}$} & 0.099 & 1.152 & {$[.249]$} \\
\hline EA & 0.212 & 2.471 & {$[.013]^{*}$} & 0.297 & 3.423 & {$[.001]^{\star *}$} & -0.01 & -0.118 & {$[.906]$} \\
\hline EM & 0.008 & 0.09 & {$[.929]$} & 0.313 & 3.577 & {$[.000]^{\star *}$} & 0.004 & 0.045 & {$[.964]$} \\
\hline WM & 0.099 & 1.139 & [.255] & 0.281 & 3.209 & {$[.001]^{\star *}$} & -0.059 & -0.68 & [.497] \\
\hline SW & 0.181 & 2.11 & {$[.035]^{*}$} & 0.203 & 2.342 & {$[.019]^{\star}$} & 0.052 & 0.603 & {$[.547]$} \\
\hline WA & -0.04 & -0.458 & [.647] & 0.391 & 4.464 & {$[.000]^{\star *}$} & -0.043 & -0.497 & [.619] \\
\hline $\mathrm{YH}$ & -0.067 & -0.757 & [.449] & 0.25 & 2.845 & {$[.004]^{\star *}$} & -0.159 & -1.801 & {$[.072]$} \\
\hline NW & -0.137 & -1.569 & [.117] & 0.266 & 3.02 & {$[.003]^{\star *}$} & -0.108 & -1.228 & {$[.220]$} \\
\hline NO & -0.221 & -2.513 & {$[.012]^{*}$} & 0.188 & 2.131 & {$[.033]^{*}$} & -0.22 & -2.498 & {$[.012]^{*}$} \\
\hline SC & 0.188 & 2.143 & {$[.032]^{*} \#$} & 0.031 & 0.355 & [.723] & -0.124 & -1.41 & {$[.159]$} \\
\hline UK & 0.07 & 0.807 & {$[.420]$} & 0.281 & 3.22 & {$[.001]^{\star *}$} & 0.035 & 0.403 & {$[.687]$} \\
\hline
\end{tabular}

\#Scotland's value is based $+4 \mathrm{Q}$. Key to regions, see Table $1, *$ sig at the $5 \%$ level, ** sig at the $1 \%$ level.

Reviewer(s)' Comments to Author:

Referee: 1

Comments to the Author

This paper is a revised version of the paper I had reviewed previously. I think the author has addressed the main comments. The remaining comment I have relates to the reference to Mundell (1961) relating to regional industrial mix.

This paper is quite old predating much industrial change in the UK and also and perhaps more importantly predating the changes in access to mortgage finance. I would argue that changes in the latter are today more important than industrial mix at the regional level specified in the 
paper. Even over the time period analyses changes in access to mortgage finance and regional differences in this access may be important. Most industries not tied to one location, except perhaps international finance and oil, so I think discussion of industrial is somewhat less important. If the authors want to keep something related to industrial mix they could refer to differences in incomes per head across regions which don't necessarily show signs of convergence. Furthermore differences in incomes could lead to differences in treatment in the mortgage market via cost of funds. This is worth exploring.

\section{Referee: 2}

Comments to the Author Manuscript 'An Application of Two Non-Parametric Techniques to the Prices of British Dwellings: An Examination of Cyclicality' (CUS-955-16-11) is a resubmission, and the author(s) have responded to the points raised by the first reviewers to revise the literature review. However, as someone coming to this fresh, I cannot help think that the title of the section "Selected literature" could be more informative and references to it in the introduction recognising how it sits alongside the review the house price and ripple effect literature.

The analysis uses the UK as the reference series whereas Cook and Watson use London but no explanation is given for this (2nd paragraph, page 13). I need to be convinced here because it is possible that the averaging process could smooth and mask the cyclical movements being investigated.

Another area I think needs to be addressed before the paper is ready to be published is the way the analysis is presented and discussed. Firstly, the table numbering should be sequential and references accordingly. I count 6 tables:

- $\quad$ Table 1 House Price Levels and Trends (Page 25)

- $\quad$ Table 2 Measures of Agreement (Page 27)

- $\quad$ Table 3 Spectral Values at the Dominated Cycles (Page 28)

- $\quad$ Table 1 The 25 Quarter Cycle (Page 30)

- $\quad$ Table 2 The 32 Quarter Cycle (Page 31)

- $\quad$ Table 3 The 45 Quarter Cycle (Page 32)

The Page 25 table matches up with the Table 1 reference on Page 14; the reference to Table 2 on Page 15 matches up with Table 2, Page 27 and Table 3, page 16 matches up with Table 3; Page 28. From the titles, the tables on Pages 30-32 appear to match up with 25, 32 and 45 periods results discussed on page 16. However, two lines down there is reference to 10.75 years in the analysis. 10.75 years gives 43 periods, not 45 so is the date wrong or has the wrong table of results been accidentally added to the paper? I think the table may be wrong as Table 3 , Page 32 has a column heading ' $10 y 3 q$ '.

The last paragraph on page 16 runs over the page. This discusses the results of the six-year cycle. However, I cannot see how the Kappa shows that Outer Metropolitan is out of phase (at least at $1 \%$ significance level). Perhaps I am reading the table wrong or looking at the wrong table but I would have thought the results of OSE (Outer South East) behaved more similar to London than OMET (Outer Metropolitan) in this table. I also think thisand the other two result 
tables could be better laid out. A key is provided in a box at the bottom of the table but why not label each row in the table to the corresponding value? This would make the results clearer.

The third paragraph down on Page 17 refers to phase values $(\mathrm{Ph})$ in Table 3. Table 3, page 28 has "Phase" but no Ph. There is a key at the bottom that refers to Ph=Phase. Why include the abbreviation at all?

The spectral analysis as on page 28 uses 6.4 years, 8 years and 10.67 years cycles so is there any reason why different cycle lengths are used in the P-T analysis? If cross-comparing would it not make better sense to use the same cycles?

\footnotetext{
${ }^{i}$ A referee notes that given the small number of complete cycles inherent in the series, inferences from longer cycles should be interpreted carefully. Indeed, rather than 43 periods, which the spectral analysis highlights, Kappa values are greater if 45 periods are used.
} 